\title{
5 Years into Augmented Reality Technology in Education: Research Trends, Bibliometric Study and its Application to Enhance Visualization Skills
}

\author{
DAYANA FARZEEHA ALI, MARLISSA OMAR, ABDUL HALIM ABDULLAH, NOR HASNIZA \\ IBRAHIM, MAHANI MOKHTAR, NORASYKIN MOHD ZAID, NUSAILA JOHARI
}

\author{
School of Education, Faculty of Social Sciences and Humanities \\ Universiti Teknologi Malaysia \\ 81310 Johor Bahru, Johor \\ MALAYSIA
}

\begin{abstract}
Augmented Reality technology allows users to interact with virtual objects integrated into the real world and real-time. Augmented Reality technology is considered a potential tool to promote the teaching and learning process. This study aims to identify the trends of publications related to Augmented Reality (AR) in education, bibliometric review of the studies as well as its application on enhancing students' visualization skills in engineering education field. Thus, this study reviewed trends and bibliometric studies focusing on Augmented Reality (AR) in education for the past five years based on the Web of Science (WOS) database, and provide experimental results on the application of augmented reality technology to enhance visualization skills among engineering students. The result from this study proves that augmented reality shows an upward trends in education, as well as the experimental findings indicates positive results in enhancing visualization skills which is one of the reason why augmented reality is frequently used in education field as teaching and learning tools. This study will also provide researchers and educators with knowledge of the research trends of augmented reality in education. This paper will then highlight the most influential authors and countries in this research area as a reference for future researcher.
\end{abstract}

Key-Words: - Augmented reality, education, teaching, learning, bibliometric, review

Received: December 6, 2020. Revised: March 14, 2021. Accepted: April 27, 2021. Published: May 11, 2021.

\section{Introduction}

Nowadays, the teaching and learning process is no longer conducted solely in the classroom. Teaching and learning can be conducted anywhere, regardless of time and place. Technology has been identified as very influential in human life today as a medium for information and communication technology. In line with, various technology has been used in education due to its benefit. The use of technology in education has grown exponentially worldwide in various educational areas such as Science, Mathematics, Engineering and Social Sciences. According to Yee et al. [1], Malaysia needs to increase the generation of scientific, progressive, competitive, significant change and forward-looking people who are technology users and contributors to scientific development and future technological development.

The current industrial revolution has impacted the education system in Malaysia in terms of its delivery and outcomes. Various parties have described the effect of the Fourth Industrial Revolution (IR4.0) on the future of education, gender and work, and the requirement of reskilling to fulfil the IR4.0 needs [2]. Fig. 1 shows the dimensions of the Fourth Industrial Revolution.

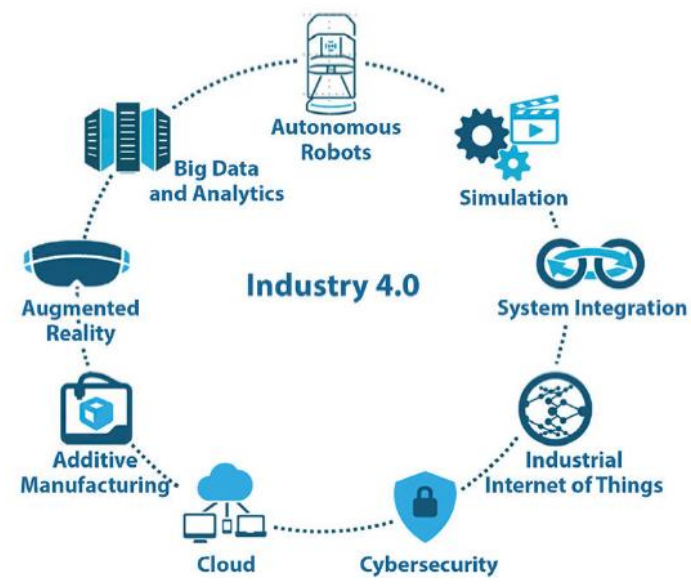

Fig. 1 Dimensions of the Fourth Industrial Revolution (IR4.0) [3] 
As the education system in Malaysian has undergone another evolution, Augmented Reality technology was introduced to ensure effectiveness in Teaching and Learning. AR has been recognized as one of the potential technologies in computer graphics [4]. AR allows users to access virtual objects into the real world in real-time. AR allows users to interact with virtual objects in a real and interactive way [5][6]. Recognizing this technology's uniqueness, many researchers found that this technology is suitable for use as a teaching and learning tool in various fields such as Science [7], Mathematics [8], Language [9] and Engineering [10].

The great potential and benefits of teaching and learning can be obtained through AR technology implementation [11] if appropriately applied. With the discovery of various benefits in using AR technology, many researchers suggest that $A R$ technology be used in education during the P\&P process [12]. Thus, this paper aims to describe the trends and conduct bibliometric studies focusing on the use of Augmented Reality (AR) in education for the past five years.

\section{Methodology}

This study aims to identify the use of AR in the education field. This paper Web of Science database to search for the articles included in this review paper. A total of 2545 publication is identified from the Web of Science database searches. The following keywords were used in the database search: "augmented reality" and education. In this study, inclusion and exclusion criteria are applied to ensure the articles included in these studies fit this review paper's criteria. The inclusion criteria and exclusion criteria are as follow:

Inclusion criteria: a. Studies published within 2017 and 2020 .

b. Studies that already in the final stage of publication in the database.

Exclusion criteria:

a. Studies published in the form of other than "Articles" in selected journals.

b. Studies comes from other than "Journal" based on the source type

c. Studies that uses other than "English" language.

After the inclusion and exclusion criteria are implemented, 792 articles have been identified and selected based on the Web of Science database. These records are then exported in the forms of txt. file format for the Web of Science database. In this review paper, bibliometric visualization methods and bibliometric analysis are used. This method is a quantitative method representing the trends of research and the characteristics of the publications [13]. For the bibliometric analysis, VOSviewer software was used to retrieve, analyze and visualize information on publications in this area. Bibliographic coupling of countries and authors were extracted and analyzed with the use of Vosviewer software.

\section{Results}

\subsection{Most cited publication}

Table 1 shows the five most cited articles in the Web of Science database. The most cited article from 2017 to 2021 in the paper by Moro et al. [14] with 115 citations, followed by Chatzopoulos et al. [15] with 74 citations. Based on the table, three out of five articles were reviewed or survey articles, while only two articles were experimental research article.

Table 1: Web of Science 5 Most Cited Articles

\begin{tabular}{|c|l|l|c|}
\hline No. & Article Title & Authors & Citation \\
\hline 1 & $\begin{array}{l}\text { The Effectiveness of Virtual and Augmented Reality in Health } \\
\text { Sciences and Medical Anatomy }\end{array}$ & Moro et al., 2017 & 115 \\
\hline 2 & $\begin{array}{l}\text { Mobile Augmented Reality Survey: From Where We Are to Where We } \\
\text { Go }\end{array}$ & $\begin{array}{l}\text { Chatzopoulos } \text { et al., } \\
2017\end{array}$ & 74 \\
\hline 3 & $\begin{array}{l}\text { A Survey of Augmented, Virtual, and Mixed Reality for Cultural } \\
\text { Heritage }\end{array}$ & Bekele et al., 2018 & 72 \\
\hline 4 & $\begin{array}{l}\text { The Past, Present, and Future o f Virtual and Augmented Reality } \\
\text { Research: A Network and Cluster Analysis of the Literature }\end{array}$ & Cipresso et al., 2018 & 61 \\
\hline 5 & Learning English with Augmented Reality: Do learning styles matter? & Hsu, 2017 & 69 \\
\hline
\end{tabular}

\subsection{Distribution by field/areas}

Table 2 shows the top 10 research field or areas for publication related to augmented reality in education.
The findings obtained from the Web of Science database shows that majority of the publication is from Education Educational Research (302), 
followed by Education Scientific Disciplines (83) and Computer Science Interdisciplinary Applications (81). Based on the findings, it can be concluded that most of the articles published related to augmented reality in education are primarily in education educational research areas.

Table 2: Publication Number Based on Research Field/Areas from Web of Science Database

\begin{tabular}{|l|c|}
\hline Field/areas & Publication \\
\hline Education Educational Research & 302 \\
\hline Education Scientific Disciplines & 83 \\
\hline $\begin{array}{l}\text { Computer Science Interdisciplinary } \\
\text { Applications }\end{array}$ & 81 \\
\hline $\begin{array}{l}\text { Computer Science Information } \\
\text { Systems }\end{array}$ & 55 \\
\hline Engineering Multidisciplinary & 46 \\
\hline Engineering Electrical Electronic & 38 \\
\hline Chemistry Multidisciplinary & 31 \\
\hline $\begin{array}{l}\text { Computer Science Software } \\
\text { Engineering }\end{array}$ & 27 \\
\hline Computer Science Theory Methods & 24 \\
\hline Environmental Sciences & 23 \\
\hline
\end{tabular}

\subsection{Bibliographic Coupling of the Countries}

Figure 2 (See Appendix) presents a network visualization of a bibliographic coupling of the countries based on the Web of Science database. A country's minimum number of publications was 7 . Of the 77 countries, 35 met the threshold. The number of publications, the number of citations, and total link strength were calculated for all countries. The countries with the highest total link strength identified in this study are the United States, with 49 total link strength, 155 documents and 832 citations. It was then followed by the People's Republic of China with 40 total link strength, 57 number documents and 388 citations. For the other countries, the number of publications, number of citations and total link strength were calculated and listed in order. The other countries were England $(37 ; 175 ; 38)$, Spain $(92 ; 652 ; 31)$, Germany $(30 ; 131 ; 20)$, Portugal $(18 ; 56 ; 20)$, Canada $(24 ; 66 ; 19)$, France $(12 ; 35 ; 17)$, Australia $(51 ; 397 ; 16)$ and Netherlands $(12 ; 33 ; 16)$. Based on figure 2, there are 7 clusters represented by a different colour, with the biggest cluster that consists of 10 countries. The countries were Cyprus, England, Greece, India, Indonesia, Italy, Malaysia, Poland, Saudi Arabia and Turkey. The second biggest cluster consists of 6 countries: Canada, Finland, Germany, South Korea, Sweden and the United States. This was followed by the third biggest cluster, which consists of Australia, Japan, Peoples Republic of China, Singapore and Taiwan.

\subsection{Bibliographic Coupling of the Authors}

Figure 3 (See Appendix) presents a network visualization of a bibliographic coupling of the authors based on Web of Science. A country's minimum number of publications was 4 . Of the 2531 authors, 28 meet the thresholds. The number of publications, the number of citations and their total link strengths have been determined for all authors. Based on these database search findings, the author with the greatest total link strength was Vahabzadeh A. from Harvard Medical School, United States, with 17 total link strength, seven documents and 84 citations. It was then followed by Keshav N. U. from the Cambridge United States with 15 total link strength, six documents and 56 citations. The number of publications, number of citations, and total link strength were calculated and listed in order for the other authors. The next author is Sahin N. T. from the Cambridge United States $(6 ; 80 ; 15)$, Salisbury, J. P. also from Cambridge United States $(5 ; 74 ; 13)$, Birt J. from Bond University, Australia ( $5 ; 54 ; 6)$, Cowling M. from CQ University, Australia $(4 ; 49 ; 6)$, Moro C. from Bond University, Australia $(5 ; 140 ; 6)$ and Stromberga, Z. from Bond University, Australia $(4 ; 140 ; 6)$. Based on the data, 3 of the authors are from the Cambridge United States, one author from Harvard Medical School, also in the United States, and four authors from Australia. In Web of Science, it can be seen that the United States and Australia are the top contributing authors in this area of research

\section{Application of Augmented Reality Technology in Engineering Field}

The researcher has conducted an experimental study to identify the effectiveness of augmented reality to enhance visualization skills among engineering students. In the study, the researcher used a mobile augmented reality application as a teaching and learning tool to maximize the learning experience and enhance the concept understanding among the students. The mobile augmented reality focuses on engineering drawing topics which allows the students to learn while training their visualization skills at the same time.

Students were divided into two groups where the first group learn engineering drawing using the augmented reality technology and the second group used the conventional method. This approach is called a pre-test post-test quasi-experimental 
research design that allows the researcher to compare two groups. In this study, the researcher will first identify the gain scores and the standard deviation based on the data obtained after the pre-test and posttest. The researcher will then identify the assumptions for equal variances by applying the Levene's Test for Equality of Variances formula, followed by the value for $t$, degrees of freedom (df) and $\operatorname{Sig}(2$-tailed) p-value. The p-value will then show whether the students learning using augmented reality technology shows significant improvements in their visualization skills compared to students learning using the conventional method.

\subsection{Formulation for Analysis of the Result}

\subsubsection{Standard Deviation}

The formula to calculate standard deviation is expressed as [16]

$$
\sigma=\sqrt{\frac{\sum\left(x_{i}-\mu\right)^{2}}{N}}
$$

where $\sigma$ is the population standard deviation, $x$ is all the value in the sample used, $\mu$ is the mean of the sample used and $\mathrm{N}$ is the number of the values in the samples.

\subsubsection{Levene's Test for Equality of Variances}

The formula to calculate Levene's Test for Equality of Variances is expressed as [17]

$$
\begin{aligned}
& W=\frac{(N-k)}{(k-1)} \cdot \frac{\sum_{i=1}^{k} N_{i}\left(Z_{i .}-Z_{. .}\right)^{2}}{\sum_{i=1}^{k} \sum_{j=1}^{N_{i}}\left(Z_{i j}-Z_{i .}\right)^{2}}, \\
& Z_{i j}=\left|Y_{i j}-\bar{Y}_{i .}\right|
\end{aligned}
$$

where $k$ is the number of different groups to which the sampled cases belong, $N_{i}$ is the number of cases in the ith group, $\mathrm{N}$ is the total number of cases in all groups and $Y_{i j}$ is the value of the measured variable for the jth case from the ith group. The test statistic, $\mathrm{W}$, is equivalent to the $\mathrm{F}$ statistic that would be produced by such an ANOVA.

\subsection{3 t-statistics}

The formula to calculate value of $t$ is expressed as [16]

$$
t=\sqrt{\frac{\mu_{A}-\mu_{B}}{\left[\frac{\left.\left(\Sigma A^{2}-\frac{(\Sigma A)^{2}}{n_{A}}\right)+\left(\Sigma B^{2}-\frac{(\Sigma B)^{2}}{n_{B}}\right)\right] \cdot\left[\frac{1}{n_{A}}+\frac{1}{n_{B}}\right] n_{B}-2}{n_{B}}\right]}}
$$

where $(\Sigma \mathrm{A}) 2$ is the sum of data set $\mathrm{A}$, squared, $(\Sigma \mathrm{B}) 2$ is the sum of data set $B$, squared, $\mu \mathrm{A}$ is the mean of data set $\mathrm{A}$, $\mu \mathrm{B}$ is the mean of data set $\mathrm{B}$, $\Sigma A 2$ is the sum of the squares of data set $A$, $\Sigma \mathrm{B} 2$ is the sum of the squares of data set B, $\mathrm{nA}$ is the number of items in data set $\mathrm{A}$ and $\mathrm{nB}$ which is the number of items in data set $\mathrm{B}$. the value of $t$ is the ratio of the difference between the sample mean and the given number to the standard error of the mean. When calculating the $t$ value, the larger the magnitude of the $t$-value will give a smaller p-value.

\subsection{Findings}

After the respondents in their respective groups is exposed to both interventions, they are required to answer the Minnesota Paper Form Board Test (MPFBT), one of visualization test to identify their

\begin{tabular}{|c|c|c|c|c|c|c|}
\hline & \multicolumn{2}{|c|}{$\begin{array}{l}\text { Levene's test for } \\
\text { equality of variances }\end{array}$} & \multicolumn{4}{|c|}{ t-test for Equality of Mean } \\
\hline & $\mathrm{F}$ & Sig. & $\mathrm{t}$ & $\mathrm{df}$ & Sig. (2-tailed) & Mean Difference \\
\hline Equal variances assumed & .064 & .801 & 4.646 & 58 & .000 & 22.66567 \\
\hline Equal variances not assumed & & & 4.646 & 51.325 & .000 & 22.66567 \\
\hline
\end{tabular}
mentally combining 2D object skills. Table 3 shows the findings from the study.

Table 3: Independent Sample Test for PSVT:R

Table 3 indicates that the independent sample test for PSVT: R test shows a large significant value of .801 $(\mathrm{F}=.064)$. Hence, the null hypotheses, which stated that the two population variances were equal, was accepted and were used to identify the significant differences. Furthermore, the value of t-test with equal variances was -4.646 at degrees of freedom $\mathrm{df}$ equal to 58. Based on the findings, it indicates that the null hypotheses are accepted as the value of $p$ is smaller than the $\alpha$ value $(\mathrm{p}=.000<0.05)$. Thus, the 
result shows that there is a significant difference in the mean score of mentally rotating 3D objects skills between the respondents in the experimental and control group. This result shows that teaching and learning using augmented reality technology is effective towards enhancing the mentally rotating $3 \mathrm{D}$ objects skills during orthographic projection teaching and learning compared to the conventional teaching method.

\section{Discussion and Conclusion}

In this paper, the articles on augmented reality in education in the Web of Science were retrieved from the database and analyzed in terms of the most cited articles and publication numbers based on research areas. The retrieved data also were analyzed and visualized through both descriptive and evaluative bibliometric analysis method. For this study, Vosviewer software was used to analyze and visualize the information needed in this paper. In this paper context, the bibliographic coupling of countries and authors were analyzed and visualized.

The findings on the most cited articles from the Web of Science database shows that Moro et al. [14] were the most cited articles with 115 citations. This article was in health science, where the author studies augmented reality and virtual reality to replace a reallife cadaver with a tablet-based application to reduce the issues of financial, ethical, and supervisory constraints on using cadaver. Findings on the cadaver's effects in learning structural anatomy towards students show that students may encourage inappropriate attitudes towards human remains and exhibit a range of emotional responses such as increased callousness and disgust [18]. Thus, the use of augmented reality and virtual reality is shown to have reduced the adverse effects and issues in this study.

Other than that, the second-highest cited articles identified in this study is an article from Chatzopoulos et al. [15] that discuss the elements in Mobile Augmented Reality (MAR), such as basics information, categorization, user interface and experience as well as its functionality (tracking and registration). This study concludes that mobile devices are suitable but not yet perfect for the augmented reality application. However, with the invention of mobile computing and wearable computers, the future of augmented reality is still blooming.

According to the number of publication results based on the research areas, it is found that most of the publication identified in this study were under the
Education Educational Research area followed by Education Scientific Disciplines. This is due to this paper's nature, where the keywords used to search the articles in this study were "Augmented Reality" AND Education. Thus, making most of the articles included in this paper from the Education Educational Research and Education Scientific Disciplines.

Next, based on the bibliographic coupling results of the countries conducted, the most influential country in this area had been the United States and the second one is the People's Republic of China. The other influential countries in this research area are England, Spain, Germany, Portugal, Canada, France, Australia and the Netherlands. The most significant cluster in this area in Cyprus, England, Greece, India, Indonesia, Italy, Malaysia, Poland, Saudi Arabia and Turkey shows that studies originated from these countries were often linked with each other than the other countries on this list.

The results related to the authors' bibliographic coupling show that the most influential author in this area of research was Vahabzadeh A. when all the criteria were taken into account. However, when looking at the number of citations, Moro C. and Stromberga Z. with 140 citations Were the leading authors, followed by Martin-Gutierrez J. with 114 citations. According to the findings, the top 4 authors in this research area were all from the United States, which shows this country's predominance in this field. Besides, most of these authors were from Cambridge University and Harvard University, which is among the world's top-tier universities.

Based on the findings on the application of augmented reality technology section, it indicates a positive result in the use of augmented reality to enhance visualization skills among engineering students. This is due to the functions of this technology to emphasize complex concept and provide an effective way to present complex information in an easy way [19]. Thus, this section further proves the effectiveness of augmented reality and why augmented reality is becoming the trend in education field.

Augmented reality is already widely used in the educational field due to its various teaching and learning benefits. However, more things to be explored on using this technology make more researchers continuously conduct more studies on augmented reality, especially in education. Even though new technology tools are more holistic and practical, but this does not eliminate the importance of old teaching and learning tools [20].

The research's trends for this technology are still increasing, and more studies were continuously 
conducted to explore this technology's potential. Thus, investing in studying this technology will unveil various advantages and their application in the future. This study has successfully shown the trends and prominent authors and countries in research related to augmented reality in education, highlighting some publications for future researchers in this area.

\section{References:}

[1] Yee, M. H., Yunos, J. M., Hassan, R., Mohamad, M. M., Othman, W., \& Tee, T. K. Penilaian Kualiti Manual Pembelajaran Kendiri Pengintegrasian Gaya Pembelajaran KOLB dan Kemahiran Visualisasi Marzano. Proceeding of the International Conference on Social Science Research, 2013, pp. 1357-1368.

[2] Penprase, B. E. The fourth industrial revolution and higher education. Higher education in the era of the fourth industrial revolution, 207, 2018.

[3] Palka, D., \& Ciukaj, J. Prospects for development movement in the industry concept 4.0. Multidisciplinary Aspects of Production Engineering, Vol. 2, No. 1, 2019, pp. 315-326.

[4] Liarokapis, F., Petridis, P., Lister, P.F. \& White, M. Multimedia Augmented Reality Interface for E-learning (MARIE). World Transactions on Engineering and Technology Education, 1, 2002, pp. 173-176.

[5] Azuma, R. T. A survey of augmented reality. In Presence: Teleoperators and Virtual Environments, Vol. 6, No. 4, 1997, pp. 355-385.

[6] Kuo, Y. T., \& Kuo, Y. C. The Role of Augmented Reality and Its Application in Education and Personalized Learning. Society for Information Technology \& Teacher Education International Conference, 2015, pp. 790-797, ISBN 978-1-939797-13-1.

[7] Huang, K. T., Ball, C., Francis, J., Ratan, R., Boumis, J., \& Fordham, J. Augmented versus virtual reality in education: an exploratory study examining science knowledge retention when using augmented reality/virtual reality mobile applications. Cyberpsychology, Behavior, and Social Networking, Vol. 22, No. 2, 2019, pp. 105-110.

[8] Kellems, R. O., Cacciatore, G., \& Osborne, K. Using an augmented reality-based teaching strategy to teach mathematics to secondary students with disabilities. Career Development and Transition for Exceptional Individuals, Vol. 42, No. 4, 2019, pp. 253-258.

[9] Redondo, B., Cózar-Gutiérrez, R., GonzálezCalero, J. A., \& Ruiz, R. S. Integration of augmented reality in the teaching of English as a foreign language in early childhood education. Early Childhood Education Journal, Vol. 48, No. 2, 2020, pp. 147-155.

[10] Noghabaei, M., Heydarian, A., Balali, V., \& Han, K. Trend Analysis on Adoption of Virtual and Augmented Reality in the Architecture, Engineering, and Construction Industry. Data, Vol. 5, No. 1, 2020, p. 26.

[11] Masood, T., \& Egger, J. Augmented reality in support of Industry 4.0-Implementation challenges and success factors. Robotics and Computer-Integrated Manufacturing, Vol. 58, 2019, pp. 181-195.

[12] Yip, J., Wong, S. H., Yick, K. L., Chan, K., \& Wong, K. H. Improving quality of teaching and learning in classes by using augmented reality video. Computers \& Education, Vol. 128, 2019, pp. 88-101.

[13] McBurney, M. K., \& Novak, P. L. What is bibliometrics and why should you care? In Proceedings. IEEE international professional communication conference, 2002, pp. 108-114. IEEE.

[14] Moro, C., Štromberga, Z., Raikos, A., \& Stirling, A. The effectiveness of virtual and augmented reality in health sciences and medical anatomy. Anatomical sciences education, Vol. 10, No. 6, 2017, pp. 549-559.

[15] Chatzopoulos, D., Bermejo, C., Huang, Z., \& Hui, P. Mobile augmented reality survey: From where we are to where we go. Ieee Access, Vol. 5, 2017, pp. 6917-6950.

[16] Reinard, J. C. Communication research statistics. Sage, 2006

[17] Gastwirth, J. L., Gel, Y. R., \& Miao, W. The impact of Levene's test of equality of variances on statistical theory and practice. Statistical Science, 2009, pp. 343-360.

[18] Francis NR, Lewis W. What price dissection? Dissection literally dissected, J Med Ethics, Vol. 27, 2001, pp. 2-9.

[19] Wu, H. K., Lee, S. W. Y., Chang, H. Y., \& Liang, J. C. Current status, opportunities and challenges of augmented reality in education. Computers \& education, Vol. 62, 2013, pp. 4149.

[20] Rodrigues, J., Farinha, J. T., Cardoso, A. M. Predictive Maintenance Tools - A Global Survey. WSEAS Transactions on Systems and Control, Vol. 16, 2021, pp. 96-109. 
Contribution of individual authors to the creation of a scientific article (ghostwriting policy)

Marlissa Omar, Dayana Farzeeha Ali and Abdul Halim Abdullah has studied the trends of Augmented reality in education

Norhasniza Ibrahim and Mahani Mokhtar has run the Bibliometric software, VosViewer and identify the findings based on the results obtained.

Norasyikin Mohd Zaid and Nusaila Johari responsible for the statistics.

Sources of funding for research presented in a scientific article or scientific article itself

This research was supported by Ministry of Higher Education and Universiti Teknologi Malaysia through Industry-International Incentive Grant (Q.J130000.3017.02M06)

\section{Creative Commons Attribution}

\section{License 4.0 (Attribution 4.0}

International, CC BY 4.0)

This article is published under the terms of the Creative Commons Attribution License 4.0

https://creativecommons.org/licenses/by/4.0/deed.en US 
WSEAS TRANSACTIONS on SYSTEMS and CONTROL

\section{APPENDIX}

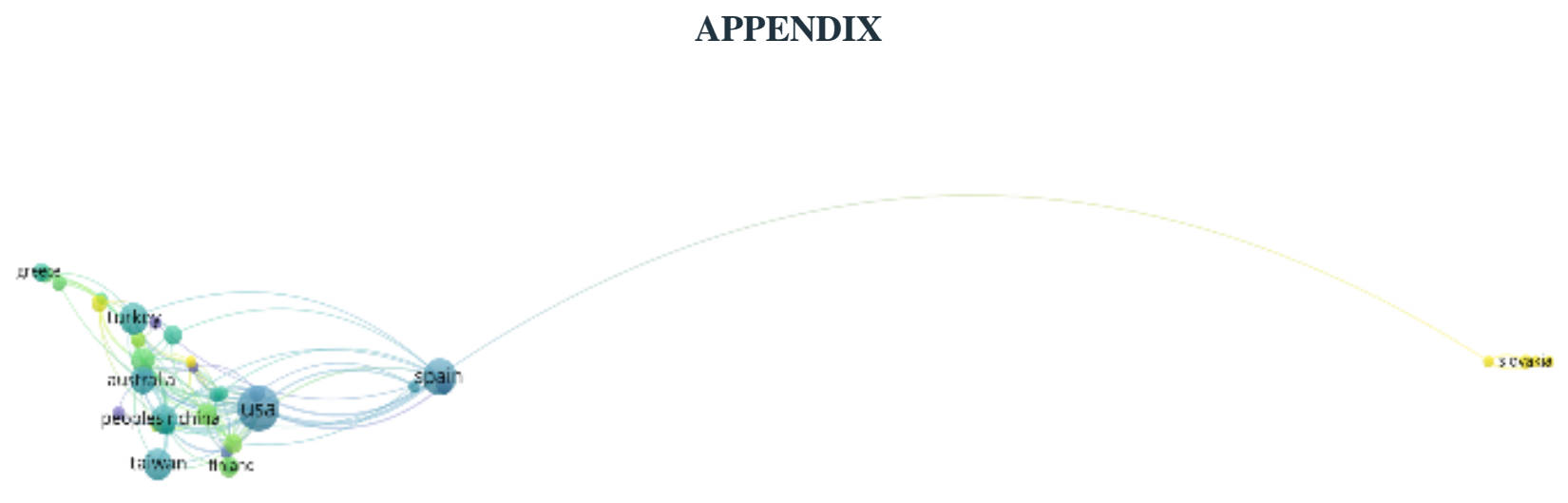

Fig. 2 Bibliographic coupling of the countries based on Web of Science database

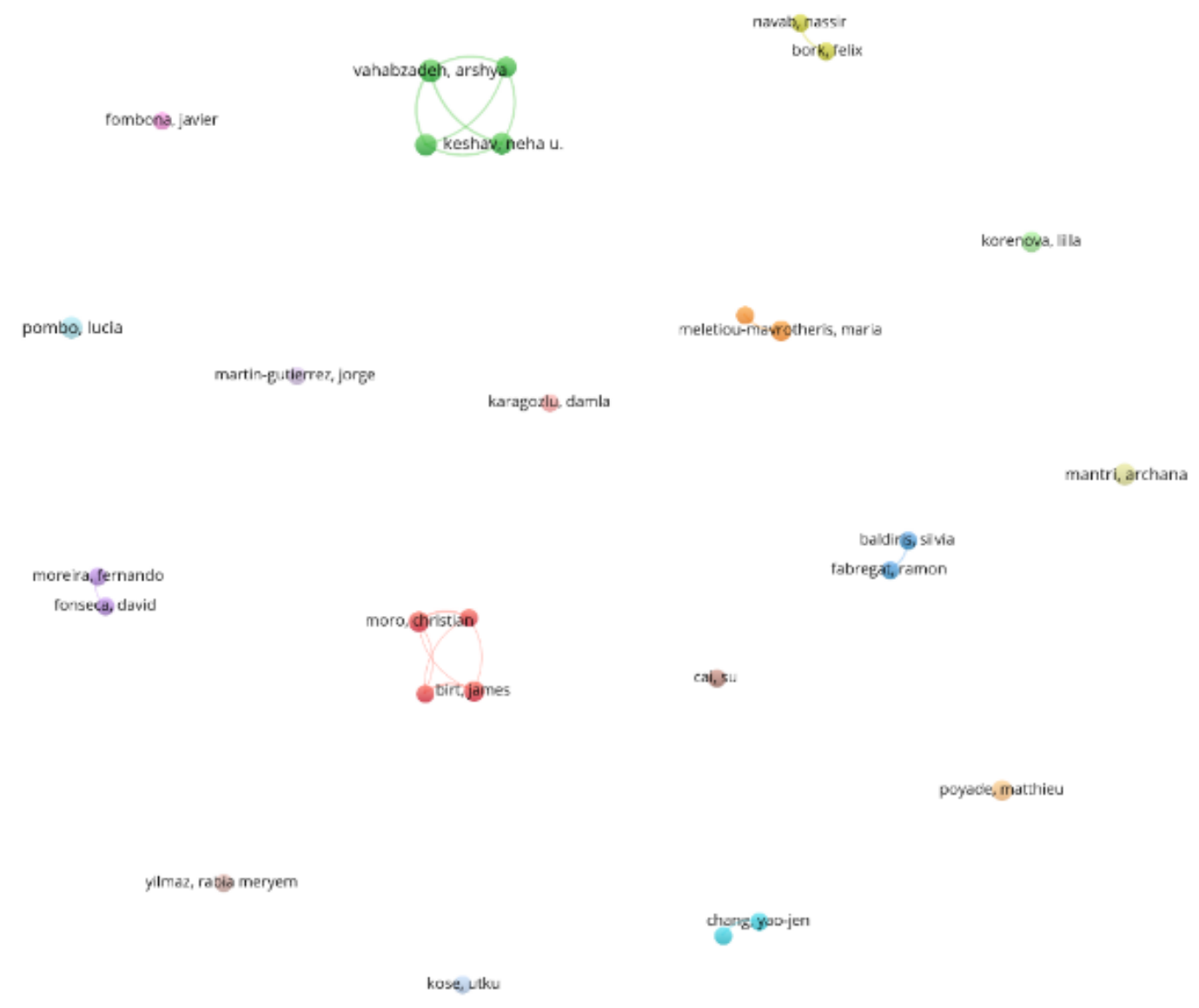

Fig. 3 Bibliographic coupling of the authors based on Web of Science database 